\title{
Ethical Issues in Transplantation
}

\section{Nicholas Tonti-Filippini ${ }^{\star}$}

Associate Dean, John Paul II institute, Lateran University, Rome, Italy

\section{Introduction}

This article is an attempt to identify the range of social and ethical issues that have developed in connection with the contemporary practice of transplantation of human tissue. Many people make the generous decision to donate organs and tissue after death and, much more rarely, some make the heroic decision to donate an organ or tissue while alive. Others suffer major organ failure and make a decision to receive an organ or tissue. Some choose to be involved in medical practice or medical research involving the use of donated organs and tissues. The issues involved in transplantation have become increasingly complex including the development of the ability to culture tissues, the development of bio banks, xenotransplantation and human-animal transgenesis and the effects of trade in human tissue products.

The author's first professional encounter with organ and tissue donation happened in the early 1980s. By then, organ transplantation was a relatively new but well established practice. Historically, solid organ transplantation had not been practiced successfully until after the development of cyclosporin in 1974. Prior to then there had been difficulty controlling immune rejection, except in circumstances of very close tissue matching. In the history of the development of the successful practice of solid organ transplantation the following were significant developments:

- Matched blood transfusion (1907)

- Anti-biotics (1947)

- Ventilator supported bodies from which to procure organs (1952)

- Steroids (1960s)

- Knowledge of histo-compatibility and immune system(1965)

- Cyclosporin (1974)

- Micro-surgery (1975)

- Statutory recognition of death by the brain criterion, so-called "brain death" (Australia, 1981)

These last three events mark the beginning of the modern era of successful transplantation.

There were transplant experiments before 1974, particularly the heart transplant experiments conducted by Christian Barnard in South Africa, but they were unsuccessful. There is a reported transplant of a leg by Sts Cosmos and Damian in the third century, but that also was unsuccessful though it is thought that they might have achieved perfusion. However the patient died, as would be expected given our current knowledge of what is needed for a successfultransplant.

Attitudes to the human body are socially, culturally and spiritually complex. During life, people identify with their bodies and emotionally they relate to others as bodies. They may see the body as sacred and inviolable. However, it is also possible that people see the body instrumentally, just as an object that they use and happen to inhabit for a time. The unity of the mind and body is something that we may have come to accept in life, but religious beliefs differ about whether there is a spiritual soul and what its relationship to the body may be.

That leads to differing views about what death is and whether the person continues on beyond bodily death, whether there is a life after death, whether the person, including his or her body may be resurrected after death, or whether the spirit may inhabit some other body in the future. What happens at death is something of a mystery. We do not observe the moment of death so much as the events that usually follow death. Consciousness is not observable and if someone has some brain function but is unresponsive, we cannot be absolutely sure whether or not they are capable of consciousness.

There are many differences in religious belief about what happens at death. Even amongst Christians, some believe that the soul dies with the body to be later resurrected for the Last Judgement, and others see death as the separation of the immortal soul, with the body no longer being formed by the immortal soul. Those differences obviously affect where we think the person is located - in their body alone, in the unity of body and soul, or in their soul. Non-believers may see the human being as matter only, with nothing of the person surviving death. Some may see death of the person as occurring when consciousness is lost, and as an event that may precede death of the body.

That range of religious beliefs complicates the medical understanding of death and when organs may be taken from the body for organ transplantation. Those beliefs also complicate which organs we think may be transplanted. Might one, for instance, attempt a brain transplant? It is not currently possible, but one day perhaps someone will attempt to prolong their lives by having their brain transplanted to a much younger body. One wonders what it would mean to wake up in another person's body. I often ask my students that if my brain were switched with one of their bodies, who would go home to my wife - my brain in someone else's body, or my body with someone else's brain? Or would neither be the person whom she married? One could well imagine a bodily gender change that would make that even more confounding.

People are usually also concerned about donating testes or ovaries because they can be used reproductively to produce genetic children of the donor. The autologous transplant of ovarian tissue has been achieved and offers hope of future fertility to women who are undergoing treatment for cancer that will affect their ovaries. The tissue can be stored in a frozen state and then returned to her after treatment. That also raises the possibility of heterologous transplant, that is, transplant of ovarian tissue to someone else.

\section{Living Donation}

Human organs and tissues can be taken after death, but some tissues may be made available while the person is still alive. Donating blood is quite common and most are aware of bone marrow donation, which is

*Corresponding author: Nicholas Tonti-Filippini, Associate Dean, John Paul II institute, Lateran University, Rome, Italy, E-mail: ntonti-filippini@jp2institute.org

Received July 05, 2020; Accepted July 07, 2020; Published July 10, 2020

Citation: Tonti-Filippini N (2020) Ethical Issues in Transplantation. J Transplant Technol Res 2:e113. doi:10.4172/2161-0991.1000e113

Copyright: (C2020 Tonti-Filippini N. This is an open-access article distributed under the terms of the Creative Commons Attribution License, which permits unrestricted use, distribution, and reproduction in any medium, provided the original author and source are credited. 
a little more difficult. Blood and bone marrow are regenerative. That is to say, they are replaced by the body.

It is also possible for people to donate one kidney and even part of their lungs or part of the liver, while they are still alive. A kidney can be donated because we are blessed usually with two kidneys and we only need about a quarter of one kidney for adequate renal function. Livers are partly regenerative, so it is possible to take part of the liver for transplant. Similarly, there are five lung lobes and it is possible to lose one without drastically affecting function. Sometimes both parents will each donate a lung lobe to a child suffering from a lung disease, such as cystic fibrosis. It is a procedure that potentially could have a triple mortality rate.

The issues associated with living donation obviously centre on protecting the donor from harm. There are also complex issues in relation to consent because living donation most often takes place within the family and involve family dynamics which could involve a person being placed under undue pressure to donate tissue, especially where that involves significant risk to themselves. A small proportion of people will face the question of donating an organ or tissues while they are still alive. Sometimes the opportunity arises because a family member is ill with renal failure, liver failure, lung failure or suffers from diseases that affect the bone marrow and its capacity to generate blood cells.

I was recently approached by a friend who had received a phone call from her sister's renal physic ian saying that her sister was not doing well on haemodialys is and desperately needed a kidney transplant. My friend contacted me but did not want to discuss the matter with her husband, as she felt he would be very negative about her being exposed to the risks of being a living kidney donor. The circumstances raised a number of questions about how such matters can be approached and whether people have a right not to be put under emotional pressure to be a living donor.

A complicating factor in living donation is the state of health of the donor. It used to be the case that organs would only be taken from well donors, but more recently where a person has been very determined to be a donor for a relative, the transplant teams have been prepared to take greater risks both for the donor and for the recipient, by taking a kidney, for instance, from someone with diabetes and already at risk of renal failure or someone who is obese and at risk.

\section{Tissue Products [1]}

A second area of organ and tissue donation is the obtaining of tissue for the purposes of undertaking research, including the culturing of tissues and storing them in what has come to be known as a bio bank. It has become possible to keep tissue alive in culture indefinitely. There are many uses of stored tissue, particularly tissue that comes from people who have particular diseases which then make it possible to study the disease in culture and the effects of various pharmaceutical agents on the disease process at the cellular or tissue level. Also tissue culture from a person who has cancer, for instance, may contain valuable antibodies that could be used to treat others. Sometimes those tissue samples will have been obtained while the person was undergoing investigation or surgical treatment.

Who owns the samples left in the pathology laboratory? How may they be used? Can they be de-identified (have information that identifies the donor removed) and be approved for use without consent to those further uses? Can de-identification be regarded as permanent when their exist genetic databases and bio banks, such as the "Guthrie samples" that involve identified blood samples from almost all children born in hospital for the past forty or fifty years? Should genetic tissue always be regarded as in principle re-identifiable as the National Health and Medical Research Council has acknowledged [2].

As well as tissue cultures, it is also possible to create other forms of human tissue products. For instance, skin can be grown in culture to treat burn victims, and it is possible to manufacture bone screws and bone paste from human bone to be used in orthopaedic procedures. In the area of cosmetic surgery and repairing tissue after trauma, there are other products such as collagen.

The development of tissue products, including living cultures, raises questions about whether they can be commercialised. In Australia we have legal and ethical restraints on trade in human tissue, but the practice of trading human tissue products has developed with very little regulation. That raises questions about whether tissue cultures are owned and can be disposed of in that way, or whether, when someone donates tissue for medical purposes, there are obligations to the donor and the wider community that indicate not ownership of the tissue but rather stewardship or custodianship. Stewardship or custodianship would imply being restricted to using tissue for the purposes for which it was donated and may exclude using the donated tissue to generate profits. If there are significant profits to be made from donated tissue then that may affect the willingness of people to donate, and may risk the extraordinary social capital that we have in Australia in the willingness of people to donate blood and bone marrow during life, and solid organs after death.

\section{Trade in Human Tissue [2]}

The issue of trade in human tissue products also raises the questions of trade in human tissue. Practices have developed in some countries, usually poorer countries, in which people travel to those countries from wealthier countries for the purpose of paying someone to donate a kidney. This is called "medical tourism". Some places prohibit trade in major organs but permit trade in skin, blood and bone marrow or corneas, or the payment for tissue used for research purposes or for developing bio banks. Some people reject trade in tissue outright because it involves treating the human body as an object to be bought and sold, rather than as sacred or inviolable. Others reject the practice because it would undermine the altruism that has developed in this area and the social capital that exists in existing organ and tissue donation practices for the purposes of transplantation.

There are also concerns that if people are paid for their organs and tissues, they may behave differently. That is called "perverse incentive". It may be the case that potential organ vendors would hide important information, such as having an "at risk" lifestyle or carrying an infection. The latter could have serious implications for the transplant recipients.

Finally, the existing systems for organ transplantation generally provide equity of access to the technology. If you are sick and in need of an organ, the decision will be made on medical grounds, not on whether you can afford to pay. Traffic in organs would remove, or at least threaten, equity of access, with organs and tissue made available on the market to those who can afford the asking price. The evidence suggests also, that traffic in organs involves obtaining organs from people who are poor and thus more easily exploited. Currently, living donors of organs and tissues are carefully monitored to ensure that the risks of harm are minimised, and that ongoing care of the donors continues well after they have donated an organ. If people are paid for their organs then it may be much less likely that there would be followup, monitoring and care of them. For these reasons, most governments 
have opposed trafficking in human organs and "medical tourism" for that purpose, but it does happen.

\section{Donation after Death}

Because of the development of transplant technology, we are often asked to face the question of whether we wish to be organ and tissue donors after we die. The technology which has been routinely available now in Western countries for at least 35 years still raises questions about how death is to be determined, and even whether we should retain what is called the "dead donor rule". There were submissions from some ethicists, to a public enquiry I chaired into the unresponsive state, which argued that people in an unresponsive state could be used as organ donors. In the medical and ethical literature, there are also differing views expressed about current practices involving diagnosis of death by the brain criterion.

For many, donation of organs after death is not cause for much reflection. Why would one not allow organs to be used for the benefit of others since they are only going to be buried or cremated otherwise?

However, there are some important discussions to be had between family members, because what happens in relation to organ donation may profoundly affect their experience of the donor's death. Most people do not die in circumstances in which solid organs can be obtained. It is still possible to donate some tissues, such as skin, bone and corneas, long after death, but solid organs such as kidneys, livers, hearts and lungs can only be used if they are taken while the heart still beats (death by the brain criterion or "brain death"), or at least very soon after the heart stops (donation after cardiac death or DCD). Both circumstances require the patient to be cared for in controlled circumstances, usually in an intensive care unit. The reason is that those organs deteriorate fairly rapidly after circulation stops unless they are immediately treated with a cool preserving solution, and in the case of death by the brain criterion, the body must be sustained on a ventilator.

Being an organ donor will change the experience for the family because, instead of being with the dying person at the time of what is ordinarily accepted as death, and afterwards, in the stillness of circulation having stopped, the heart will actually stop beating in the operating theatre and the relatives will not be present when that happens. In both donation after death by the brain criterion has been diagnosed, and donation after cardiac death, the family make their goodbyes, while the heart till beats, usually in the intensive care unit and prior to the patient being taken to the operating theatre. There is also some urgency about completing consent to organ donation and adequately informing the relatives about what is to occur, because the organs do have to be obtained within a relatively tight timeframe. Once the brain ceases to function, circulation usually ceases within a relatively short period of time. So-called "brain death" is not usually a stable state.

In recent times we have seen some developments in relation to diagnosing death by the brain criterion. The US President's Commission in 2009 rejected the long held religious belief that accepted that loss of all brain function meant loss of integration of the body in the sense that the organs were no longer related to one another as a singly functional unity. The brain was thought to mediate the neural and endocrine systems that communicate between the different organs and cause the system to function as a single unified entity. The Commission instead adopted what it called a "mode of being" view in which death could be diagnosed on the basis of permanent loss of consciousness and loss of spontaneous breathing, even if some brain functions were retained. That is deeply troubling because death of the brain stem is not loss of all function of the brain and some consider such a person to be disabled but still alive in the sense that the body remains integrated. There has been a parting of the ways between religious and some secular concepts of what death is [3].

Finally, what happens to the body after death can be very emotional for some people? Some cultures reject disturbing the body after death for organ procurement. Politically, there are issues to do with the status of the body after death. In some jurisdictions the body becomes the property of the State after death and consent to organ donation is presumed. In those jurisdictions the family usually has a right to conscientiously object, but otherwise consent is presumed.

Currently in many jurisdictions, consent is required for organ donation. The latter is often called "contracting in", as opposed to presumed consent, which is called "contracting out". There is often public discussion about switching from contracting in to contracting out. Some argue that it would improve donation rates. However the evidence is mixed. Sweden, for instance, has contracting out but a comparatively low donation rate.

\section{Donation after Cardiac Death}

As mentioned above, the donation of solid organs has largely depended on diagnosis of death by the brain criterion, and, in reality, in only approximately $2 \%$ of deaths might the person be a donor of solid organs after death, because most people do not die while being ventilated. Most deaths happen through loss of circulation and in those circumstances the solid organs rapidly deteriorate. Some tissues, such as bone and corneas, can be removed for donation a long period after death, but major organs such as hearts, lungs, livers and kidneys rapidly deteriorate. The fact that a very small proportion of people are diagnosed by the brain criterion when they die has led to greater emphas is on trying to recover organs from people who die following loss of circulation, so-called "donation after cardiac death" or "DCD".

There are new issues in DCD because the most common circumstance involves preparing to use organs from someone who is not yet dead, but is likely to lose circulation soon after life support treatment is withdrawn in controlled circumstances. That raises questions about the independence of and reasons for the decision to withdraw the life support treatment, and it also raises questions about procedures that may be undertaken before death to preserve organs after death, such as administering anti-clotting agents or placing catheters into the femoral arteries so that a cooling solution can be rapidly deployed to preserve organs. There are also concerns when taking organs soon after circulation has stopped, that it might still be possible to resuscitate and restart circulation. There is a question over whether loss of circulation must be irreversible as the law states, or where it is good enough that it be permanent because no-one is going to attempt resuscitation. The practice may be ahead of the law in many jurisdictions. The law in most Western jurisdictions still requires irreversible cessation of circulation, but the medical practice and policy in some countries allows organs to be taken after a mere two minutes of a "flat-line" ind icating cessation of circulation, when the cessation may be permanent but not necessarily irreversible [4].

\section{Saviour Siblings}

Complicating the issues involved in living donation is the prospect of what the media have popularly called, "saviour siblings". This is where parents use reproductive technology and the capacity to test human embryos in order to deliberately become pregnant with a child who is matched so as to be a potential donor for an existing member of 
the family, often a sibling. The circumstances can be very challenging for parents in being led to make decisions that may benefit one child while endangering another, and there are also questions asked about the motivation for having a child to be of use in this way for an existing family member. Is it significant whether the potential beneficiary is another sibling or an older member of the family, perhaps even one of the parents?

\section{Recipients}

At the other end of all these technological options, are people who suffer from illnesses which may be treated using organs or tissues obtained from someone else's body. There are many complexities for someone placed in that position. The medical benefits may be so great that they can tend to obscure the reality of having placed inside one's body, parts of someone else's body, and what that means for one's own image and identity of oneself. There are no simple answers.

There may also be concerns about the way in which those organs and tissues have been obtained and the ethical propriety of practices over which the recipient has no control. If the organ or tissues are obtained from someone who is alive, then that raises significant issues for the nature of their relationship and potentially some sense of proprietorship on the part of the donor in relation to tissues that are now part of the recipient's body. If my brother gives me a kidney, how might that affect our relationship? Consider all the possible emotional implications if either of us is subsequently ill or a kidney fails for either of us, or if my lifestyle is less than ideal and contributes to my ill-health.

In receiving tissues after someone has died, the anonymity of the donation may mean that the recipient may fantasise about who the donor was and what it means to have their organ within one's body. When donation crosses gender and racial lines that may be quite confusing, depending on the person's attitudes to those differences. There may be similar fantasies by the families of donors who may perceive that their relative somehow continues through the survival of their body parts in others. Hearts and corneas may be more likely to provoke that thought.

I know of a New Zealand family in which, through having discovered the identity of the recipient of their daughter's liver, the donor family more or less adopted the recipient who was a young woman and, at the time, approximately the same age of the daughter whom they had lost. She came to live with them so that she could attend university in their home city. There appeared to be an extraordinarily complex emotional relationship between the donor family and the recipient of their daughter's liver.

\section{Manufacturing Stem Cells}

There are issues discussed in relation to reproductive technology about using the technology to develop embryos, including by the process known as cloning. That involves a sharp controversy over the status of human embryos and deliberately producing an embryo to be a source of tissue and destroyed. However, separate from the reproduction issues is the new technological capacity to develop Induced Pluripotent Stem (IPS) cells from ordinary human cells and then culturing them in a laboratory for the purposes of research and therapy. There is a range of new issues associated with this technology including issues to do with treating sperm and eggs before fertilisation, or before cloning, in order to render them incapable of developing as an embryo. That raises issues about whether the entity so formed is a disabled embryo or not an embryo at all.

\section{Genetic Research}

Genetic research using tissue, obtained before or after death, concerns not just the person who donated the tissue, but their blood relatives. Information about one person's genetics also has implications about those with whom they share genes. That could be immediate family, but it might also be wider group, such as a group identified by a particular genetic disease, or carriers of the gene for that particular disease. It might be relevant to a group who, through racial or other reasons, have been relatively isolated over several generations or more and thus have interbred and thus be more likely to have certain genetic conditions. That may lead to claims being made about them as a group related to those greater risks. Thus for, for instance, a particular disease might be found more often in an indigenous or other racial or social grouping, thus statistically affecting the risk assessment of the whole group.

A genetic test for one member of the immediate family, or other blood relative, may have significant implications for future opportunities to those others, economically, financially, in employment and in education. Wherever a health status question is asked such as in applying for a mortgage, seeking a job or job training, apprenticeships, scholarships or bursaries for education, or applying for superannuation or personal insurances, such as disability income support, crisis cover, death or disability entitlements, then a genetic test of that person or even of a relative may affect eligibility. Knowledge that one may be a carrier of a genetic disease may affect plans to marry, and after marriage it may involve pressure to seek invasive testing during pregnancy to create the opportunity for termination of a pregnancy identified with a genetic abnormality.

A genetic test may be profoundly life changing for the individual and others and lead to various forms of genetic discrimination. I know this only too well having been diagnosed as a very young person with a disease that may have a genetic basis, and which prohibited access to a range of post-graduate scholarships and became a question for insurances, for mortgage applications and for employability. At the time I was not sick, I just had an identified auto-immune disease which was predicted to be likely to cause problems in the future, including an early death. In fact the predictions were largely wrong as I have worked full-time ever since, despite illness, and lived well beyond those early predictions. My history presumably will affect my children because the questions asked of them will expose that history. Insurers, banks, superannuation companies, potential employers and others will no doubt look at their potential for renal disease in a discriminatory way, and not what I actually achieved, despite illness and disease.

As the technology develops, genetic profiling is predicted to become more common and cheaper. This will include not just diagnosis of actual conditions, but a propensity for disease, that is, the statistical probabilities about developing any of a number of major diseases possibly resulting in disability or death. A person may have a grim prediction for disease, but never actually develop any of the diseases for which they have a greater propensity. In the meantime they can be severely disadvantaged financially and for employment opportunity, and so too might their children be disadvantaged.

When tissue is obtained for a purpose such as for diagnosis of illness or disease or as part of a surgical procedure, it might then be used for genetic research with or without specific consent, and that may have grave implications not only for the individual but also his or her connections. That is especially so given the fact that human tissue always remains, in principle, re-identifiable. It was very significant recently that a UK man, who was the result of his mother using an anonymous 
sperm donor, was able, with the assistance of an agency specializing in genetic tracing, to track down his father despite the barriers that had been erected to that happening. The donor person's genes were matched to a brother of the sperm donor through the brother having had a genetic test and his details being available in an identifiable way on a private genetic data bank. Once having identified someone in the family, it was relatively easy to track the family member, who was a medical student at the time of conception, and thus likely to be the donor. The existence of genetic tissue and data banks, linked as they are for research purposes to the phenotypic (medical) record of the individual, makes identification of a person's genes or tissue possible if any of their blood relatives happen to be on one of those databanks.

\section{Xenotransplantation, Hybridisation and Transgenesis}

The matter of transplanting tissue from animals, xenotransplantation, raises safety issues in terms of spreading animal diseases into the human population. In some cases it is a wellestablished practice in, for instance, the use of pig heart valves. The valve is so treated that it loses its cellular structure and so may not cause the recipient's immune system to recognise it as a foreign body. It is thus not rejected by the immune system. However more complicated solid organ transplants from animal sources, including hearts, lungs, livers and kidneys have proved to be more problematic.

One possibility that is being developed is that of altering the genetic constitution of an animal embryo in vitro to remove animal genes and to add human genes by a process called "human-animal transgenesis" [5]. That means the creation of an embryo that began as an animal embryo but has become part human and part animal, a human-animal hybrid, so to speak. The aim would be to have the embryo matured by transferring it to the uterus of an animal until it could be born and matured, and as an adult have adult organs that might be transplanted into humans without rejection. Is there something wrong with forming a human-animal hybrid in this way? How many human genes might be added to an animal embryo before it is no longer considered an animal? Are there particular genes that are crucial to retaining a distinction between a human being and an animal? Is this something that should be prohibited, and if not what are the limits, if any, to be imposed? Are there questions about the genetic integrity of an animal species that need to be addressed, particularly bearing in mind that such changes may well be inheritable?

The possibilities for human cloning and human-animal transgenesis raise a number of concerns about how a person's tissue might be used, especially if it has been "de-identified" and specific consent no longer required. Because of the possibility of being re-identified, human tissue should never be considered to be permanently de-identified, but ethics committees do not always base their decisions on the implications of the latter and the ramifications for tissue donors and their blood relatives.

\section{The Complexity of Organ and Tissue Donation}

From all this, it is clear that donating organs or tissue before or after death, and for the purposes of diagnosis, treatment or medical research, may involve a range of complex issues as the possibilities for use have expanded including commercial uses. It is important that potential donors think carefully about what they are proposing and what may happen in the future with their tissue or products developed from it.

It is important that they discuss a donation decision with their family so that everyone is aware what may be involved and what the expectations were. There are also issues about what ethical guidelines might be promulgated that would give confidence to people about how their tissue might be used, and how the various industries that use human tissue and human tissue products might be regulated. In most Western jurisdictions there are Human Research Ethics Committee (HREC) or Institutional Ethics Committee (IEC) systems in place that are required to conform to the national guidelines. However, compliance is largely a matter of honour. Is honour enough? Also the systems may rely on government funding contracts, but only a proportion of research is government funded and hence, apart from some privacy law requirements, most private research is not subject to HREC or IEC approval. Further, many of the applications of human tissue discussed are not research applications, but involve medical treatment or may involve cosmetic or other uses of the tissue or tissue products, such as artistic uses. There is little regulation to protect the interests of donors of tissue and the community relies on the good sense of people engaged in the area. In the current climate of commercialization of human tissue products, the investment in technological developments, and the individualisation of ethics, can we be confident in that good sense and the limited application of peer review systems?

\section{Emotional, Religious and Theological Issues}

Despite the medical advances and the benefits of organ and tissue donation, people do puzzleover the meaning of the humanbody. If my body is part of my identity, what does it mean if parts of my body have come from someone else's body? In the Christian tradition, there is a notion of the unity of the body and soul in which the soul gives form to the matter in the formation of the body. What happens to that soulbody unity following having rec eived human tissues or human organs?

Some faiths have been known to reject blood transfusion for religious reasons, usually on the basis of the interpretation of some Scriptural passages. Jehovah's Witness believers have often referred to an interpretation of the Acts of the Apostles 15:20 which is translated as "Instead we should write to them, telling them to abstain from food polluted by idols, from sexual immorality, from the meat of strangled animals and fromblood."

Should that decision be respected? What happens if the recipient is a child? May parents endanger the child's life by refusing a lifesaving transfusion?

If blood transfusion is an issue, the surgeons may choose different methods of surgery to achieve "bloodless surgery" not involving such blood loss that transfusion is needed. Adults refusing transfusion may opt to take a greater risk of dying, but a child? If a person can no longer make their own decisions, might a refusal by their representative be challenged because it is not in the patient's best interests? In one case with which I was involved, the patient who was bleeding very heavily after child birth and had refused transfusion had her decision overridden by her husband after she was judged to be unable to make further decisions. The decision was supported by a tribunal. The superior courts refused to hear a subsequent application by the woman and her Church for review of the decision.

\section{Summary}

Transplantation has become increasingly complex as the technology has developed new possibilities. It is a challenge for communities to try to keep up with the science and to develop ethical and social responses. It is important that those who lead the way in the science seek to devote some time and energy to keeping the community informed. Those who hold positions of leadership in our community also have a responsibility to seek to be well informed, not to scaremonger, and to seek to provide guidance to those who are entrusted with the science. 
Citation: Tonti-Filippini N (2020) Ethical Issues in Transplantation. J Transplant Technol Res 2:e113. doi:10.4172/2161-0991.1000e113

Page 6 of 6

\section{References}

1. Nicholas Tonti-Filippini (2012) About Bioethics: Transplantation, Biobanks and the Human Body. Connor Court, Ballan, Australia.

2. Tonti-Filippini N, Zeps N (2011) Trade in human tissue products. Med J Aust 194: 263-265.
National Health and Medical Research Council (2007) National Statement on Ethical Conduct in Human Research. Australian Government.

4. Tonti-Filippini N (2012) Religious and secular death: A parting of the ways. Bioethics 26: 410-421.

5. Organ and Tissue Authority (2010) National Protocol for Donation after Cardiac Death. Australian Government. 